\section{Vertex potentials associated with an auditory discrimination*}

\author{
SHIRLEY K. HIRSH† \\ Central Institute for the Deaf, St. Louis, Mo. 63110
}

The task of making a fairly difficult auditory discrimination usually enhances the $N_{1} 0_{0} v_{0} \cdot P_{1} \overrightarrow{7}_{5}$ vertex potential evoked by the stimuli, as previously reported. In this situation, a high proportion of individuals also develops a late $(300-375 \mathrm{msec})$ positive component in their responses. There is much variability among individuals in the degree of enhancement of $N_{1} \tilde{o}_{0}-P_{1} z_{5}$ and in the prominence of $P_{30}$. These two effects of the difficult task are not clearly correlated with one another or with the success of the Ss in making the discrimination.

In 1964 Davis published a brief report based on a relatively small number (six) of Ss, which stated, "the averaged slow response evoked by auditory stimuli and recorded from the vertex of the human skull can usually be enhanced by requiring the listener to make a rather difficult a uditory discrimination. An easy routine is not effective." This report has been cited frequently in agreement, disputation, and/or extension (Desmedt et al, 1965; Donchin \& Cohen, 1967; Karlin, 1970; Mast \& Watson, 1968; Näätänen, 1967; Nielsen et al, 1970; Ritter et al, 1968; Ritter \& Vaughan, 1969; Satterfield, 1965; Sutton et al, 1965, 1967 ). In similar experimental situations, the resolution of uncertainty about a stimulus is often attended by a strong positive component, with a latency between 300 and $500 \mathrm{msec}$, in the evoked response (Sutton et al, 1965, 1967). Since, in the study by Davis (1964), an epoch of only 375 msec was sampled, the late component could not be identified. Therefore, it was decided to replicate the study with a larger population and an extended duration of the response sampled for assessment of late positive components. SUBJECTS

The Ss were 10 college students and 5 members of the Central Institute for the Deaf Research Department, 10 men and 5 women, ranging in age from 21 to 73 years. Twelve of the 15 were young adults. Four were completely naive as Ss, 8 were somewhat experienced, and 3 were highly experienced.

\section{PROCEDURE}

The $\mathbf{S}$ sat in a comfortable chair in a lighted room, facing a loudspeaker at a

*This research was supported by Public Health Service (or PHS) Grant No. NS-03856 from the National Institute of Neurological Diseases and Stroke.

+ The advice and assistance of Dr. Charles S. Watson in the preparation of the punch-paper tapes and the analysis of the data and of Dr. Hallowell Davis in preparing the manuscript are gratefully acknowledged. followed by three $1,200-\mathrm{Hz}$ tone bursts $(20 \mathrm{msec}$, with $1.5-\mathrm{msec}$ rise and fall times), all presented at approximately 60-dB sensation level. The tones in the cycle were: $A$, a warning $(600 \mathrm{~Hz})$ that the cycle was beginning; $\mathrm{B}$, the standard $1,200-\mathrm{Hz}$ tone; $\mathrm{C}$, the test tone (also $1,200 \mathrm{~Hz}$ ), which was either the same intensity as $\mathrm{B}$ or different by $\pm 3 \mathrm{~dB}$; and $\mathrm{D}$, a control $(1,200 \mathrm{~Hz})$, always the same intensity as $B$. The tones were separated by equal intervals of $2.5 \mathrm{sec}$ so that one cycle required $10 \mathrm{sec}$. Thirty-two cycles constituted one trial. Responses to Tones A, B, C, and $D$ were collected and averaged in four separate sections of the computer's memory. The averages were displayed on the computer's oscilloscope and written out on an X-Y plotter (Omnigraphic HR $96 \mathrm{Z}$ ).

Sequences of stimuli were programmed on punched-paper tape. The tape reader also triggered the computer. Four to 10 increments and the same number of decrements of $3 \mathrm{~dB}$ were added to $\mathrm{C}$, the test tone, according to a random schedule, but with the constraint that there be an equal number of increments and decrements in each trial.

There were four types of trials. In a control trial $\mathrm{S}$ sat reading. He was instructed to pay no attention to the stimuli. In a buttonpress trial, he was instructed to listen to the stimuli and to press the signal button in the interval between $\mathrm{C}$ and $\mathrm{D}$ in each cycle. In a counting trial he was asked to count the number of As presented (one or two were purposely omitted)

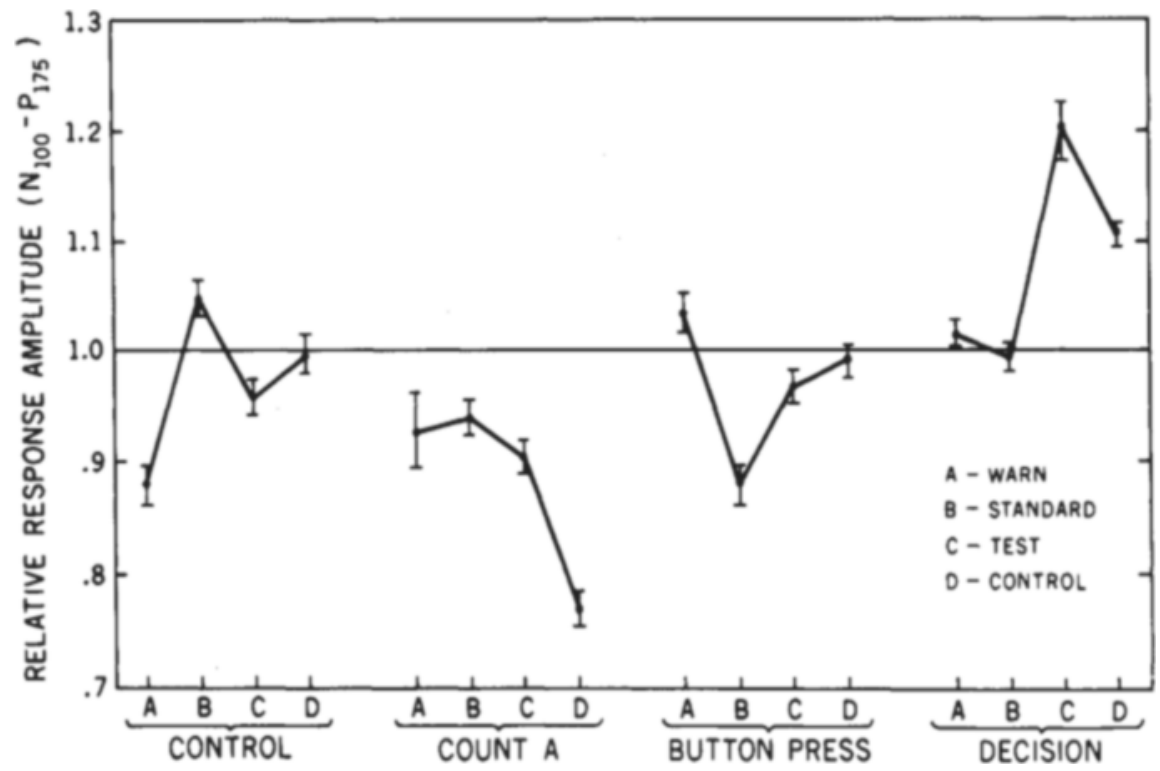

Fig. 1. Mean performance of all Ss for each condition represented as a fraction of typical performance for all conditions. Vertical bars above and below each point show one standard deviation above and below that mean. Response to Test Tone $\mathrm{C}$ in decision trials is markedly enhanced. 


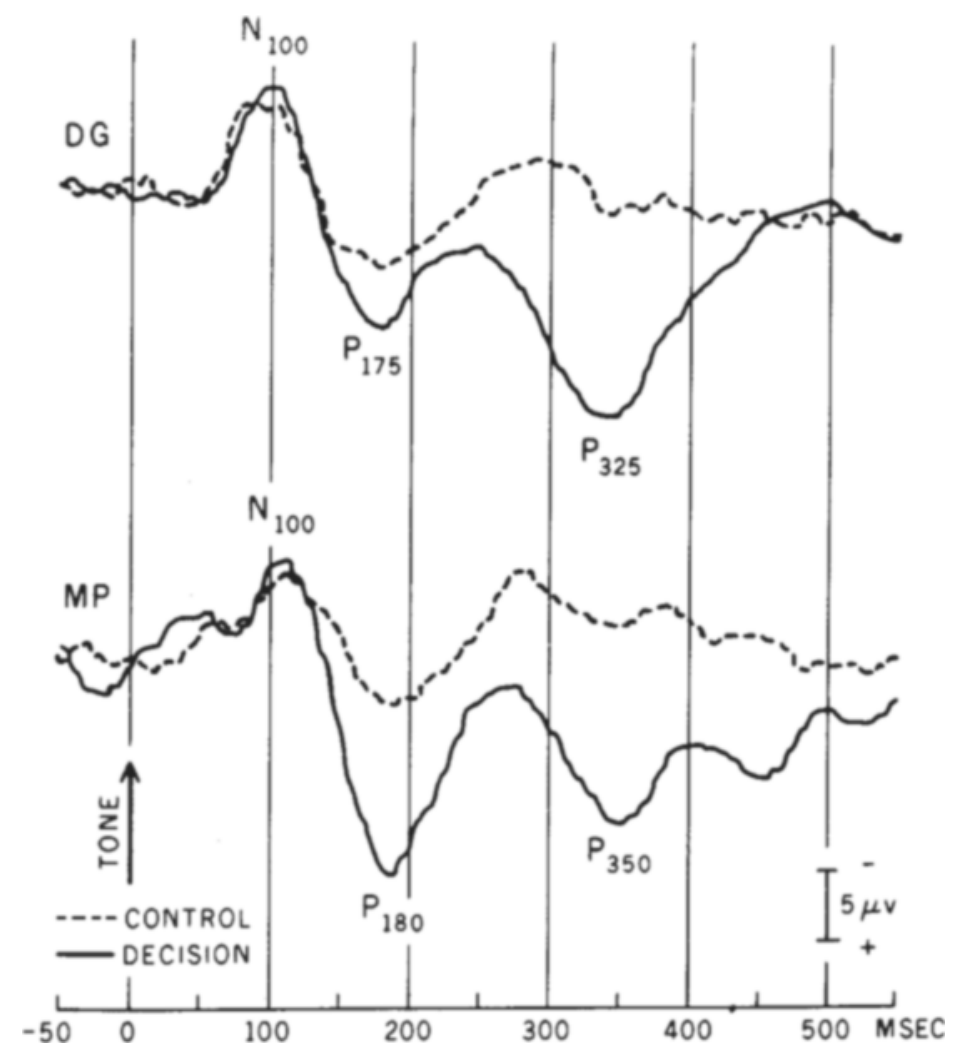

TIME AFTER STIMULUS

Fig. 2. Responses of two $\mathrm{Ss}$ to Test Tone $\mathrm{C}$ in decision and control trials. Both LPC and enhancement of $N_{1} \tilde{0}_{0} \cdot P_{1} \tilde{7}_{5}$ appear in decision trials. DG shows no alpha rhythm in his EEG background; MP shows strong and consistent alpha waves.

and report the number at the end of the trial. In a decision trial he was asked to signal in the interval between $\mathrm{C}$ and $\mathrm{D}$ if he detected a difference between $\mathrm{C}$ and $\mathrm{B}$, the standard tone.

At the beginning of an experimental session, $S$ was given practice with the signal button until he could press it with force sufficient to close the contact but with a minimum of muscle artifact in the EEG tracing. The complete session began and ended with control trials and included one buttonpress, one counting, and three decision trials. In one of the decision trials, $\mathbf{S}$ was asked to signal whenever $\mathrm{C}$ was different from $\mathrm{B}$; in another, whenever $C$ was stronger than $B$; and in a third, whenever $C$ was weaker than B. Score was kept of hits, misses, and false positives, and $S$ was informed of the general level of his performance after each trial.

The Ss found the counting task easy. Three who failed to score $100 \%$ admitted to "woolgathering." The decision task was difficult, but only one $S$ failed to make at least one perfect score, one succeeded only once, nine made two out of three, and four correctly detected all increments and decrements. Consensus of the $\mathrm{Ss}$ was that detection of the $3-\mathrm{dB}$ decrement was a harder task than detecting either the $3-\mathrm{dB}$ increment or a $3-\mathrm{dB}$ difference in either direction. $N_{100}-P_{1} \tilde{7}_{5}:$ Decision Effect

The mean amplitude of the response $N_{10} \tilde{0}_{0}-P_{1} \tilde{7}_{5}$ over all stimuli was calculated for each $S$; the mean amplitudes of the responses to Tones $A, B, C$, and D for each trial condition (control, buttonpress, counting, and decision) were then expressed as percentages of his overall mean response. Finally, the overall relative amplitude for each experimental condition was expressed as the averaged percentage, calculated for all $\mathrm{Ss}$, for that condition. The results are shown in Fig. 1.

The overall response to the test tone, $\mathrm{C}$, in the decision trials is enhanced, as it was in the Davis (1964) experiment. Twelve of the $15 \mathrm{Ss}$ showed the enhancement $(p<.05), 2$ gave equivocal results, and 1 showed a negative change. There was no significant enhancement of response to
$C$ or $D$ in the buttonpress trial. although some enhancement due to myogenic components or to anticipation had been expected Actually, the 2.5-sec interval allows time for "press after $C$ and before D" without appreciable myogenic contamination of the preceding or following evoked potential.

There was only a slight relation between level of performance and enhancement of response to the test tone in decision trials. The four Ss who made perfect scores all showed markedly enhanced responses to the test tone. Of the nine who scored $100 \%$ on two trials out of three, four gave markedly enhanced responses, and two, plus the $S$ who made a perfect score only once, gave slightly enhanced responses. The $\mathrm{S}$ who failed to make even one perfect score nevertheless showed a distinctly enhanced response to the test tone. $\mathrm{N}_{10} \tilde{0}_{0}-\mathrm{P}_{1} \tilde{7}_{5}$ : Other Effects

Smaller effects, including the depression of response to Stimulus A (for $11 \mathrm{Ss}$ ) in the control trials, to $\mathrm{D}$ in the counting trials (for $10 \mathrm{Ss}$ ), and to $B$ in the buttonpress trials (also for 10 Ss) had not been predicted. However, all of them can be given interpretations consistent with a general theory of arousal (Karlin, 1970).

In Fig. 1 it appears that the overall responses to the control and the buttonpress trials are very similar. The enhanced response to $B$ in the control trials may reflect the arousal effect of the pitch change, whereas in the buttonpress trials, attention is apparently directed to $\mathrm{A}$, the "get ready" signal. Overall response in the counting trials is depressed, with $\mathrm{C}$ and $D$ reflecting a progressive relaxation. Although each trial condition shows at least one internal variation in response amplitude of $13 \%$ to $17 \%$, the response to $\mathrm{C}$ in decision trials is enhanced $20 \%$ above the mean amplitude of all responses. The mean amplitude of all responses in the decision trials is $5.5 \%$ above the overall mean, whereas all the other conditions have means below the overall average.

Late Positive Components (LPC): Identification

Each S's monitor EEG chart was examined carefully for blink artifacts coincident with either stimuli or buttonpresses, for myogenic artifacts, and for amount of alpha (10/sec) rhythm in the ongoing EEG background. Only one S showed more than occasional random blink artifacts, and he, highly sophisticated in evoked response experimentation, had taken care to blink in the intervals between stimuli. Five $S$ s had strong (shows occasionally in vertex-to-mastoid 
recording with eyes open) background alpha rhythms, two had moderate (shows in vertex-to-mastoid recording only with eyes closed) alpha, and eight showed little or none.

The responses of each $S$ to all stimuli in decision and control trials were also examined for late (300-500 msec) positive components (LPC). All responses in all trials of the seven Ss who showed alpha rhythm in the EEG background were examined with special care, since such a background, when averaged, often produces a naturally rhythmic response which could easily be confused with LPC.

Latency of LPC has been reported to vary from one individual to another over the range from 300 to 500 msec. Of the 28 LPCs identified in our data, 9 had a latency to peak between 290 and $310 \mathrm{msec}, 13$ between 340 and $360 \mathrm{msec}$, and 6 between 365 and 385 msec. It seems that " $P_{3} \tilde{0}_{0}$ " is a reasonable identification of this component.

LPC: Decision Effect

Nine Ss showed LPCs in their responses to the test tone, $\mathrm{C}$, in at least two out of three decision trials, four showed LPC in one of three trials, and two did not give an identifiable LPC (although these two did show consistently enhanced $N_{1}$ o o $-P_{1} \ddot{7}_{5}$ responses to the test tone in decision trials). See Fig. 2.

Two of the Ss who showed strong alpha in EEG background also showed rhythmic averaged responses to all stimuli. On decision trials, both enhanced the response to the test tone, one gave a clear LPC and the other did not. The three remaining strong-alpha Ss showed only slight intrusions of the rhythm in their responses and all gave identifiable LPCs. One of the two moderate-alpha Ss gave no indication of the rhythm in his responses and only one identifiable LPC, while the other showed rhythmic responses in most trials but not to the test tone or to the control tone immediately following it in the decision trials. He produced consistent LPCs.

\section{DISCUSSION}

Individual variation within a general trend seems the best description of the enhancement of the vertex $N_{1} \tilde{o}_{0}-P_{1} \tilde{7}_{5}$ response and the appearance of the late positive component, $\mathrm{P}_{3} \tilde{o}_{0}$. Seven of 10 males and 4 of 5 females gave an enhanced response to the test tone in decision trials. Eight of 10 males and all 5 females produced identifiable LPCs in at least one decision trial. One $S$ gave a consistently enhanced response to the standard tone in the decision trials, but not to the test tone. Several Ss gave LPCs in their responses to the control immediately following the test tone in decision trials. When this was noted, $\mathrm{S}$ was asked at the end of the session whether he had been attending to the control as well as to the test tone. In each case, $\mathbf{S}$ reported that he was systematically checking his decision on the previous tone. In these cases, a "resolution of uncertainty" (Sutton et al) seems clear.

\section{REFERENCES}

DAVIS, H. Enhancement of evoked cortical potentials in humans related to a task requiring a decision. Science, 1964,145 , $182-183$.

DAVIS, H., MAST, T., YOSHIE, N., \& ZERLIN, S. Slow response of the human cortex to auditory stimuli: Recovery process. Electroencephalography \& Clinical Neurophysiology, 1966, 21. 105-113.

DESMEDT, H. E., DEBECKER, J., \& MANIL, J. Mise en evidence d'un signe électrical cerebral associé à la détection par le sujet. d'un stimulus sensoriel tactile. Bulletin de l'Académie Royale de Médicine de Belgique, 1965, 5, 887-936. DONCHIN, E., \& COHEN, L. Averaged evoked potentials and intramodality selective attention. Electroencephalography \& Clinical Neurophysiology, 1967, $22,537-546$.

KARLIN, L. Cognition, preparation and sensory-evoked potentials. Psychological Bulletin, 1970, 73, 122-136.
MAST $T$ E WATSON, C. S. Attention and auditory evoked responses to low detectability signals. Perception \& Psychophysics, 1968, 4, 237-240.

$N \ddot{A} T A N E N$ S Selective attention and evoked potentials. Annales Academiae Scientarium Fennicae, Helsinki, 1967, B 151, 1, 1-226.

NIELSON, D. W., TEAS, D. C., \& IDZIKOWSKI, R. P. Variation in cortical evoked responses as a function of evoked responses as a function of Psy chophysics, $1970,8,29-32$

RITTER, W., VAUGHAN, H. G., JR., \& COSTA, L. Orienting and habituation to auditory stimuli: A study of short term changes in averaged evoked responses Electroencephalography \& Clinical Neurophysiology, 1968, 25, 550-556.

RITTER, W., \& VAUGHAN, H. G., JR. Averaged evoked responses in vigilance and discrimination: $A$ reassessment Science, 1969, 164, 326-328.

SATTERFIELD, J. H. Evoked cortical response enhancement and attention in man. A study of responses to auditory and shock stimuli. Electroencephalog raphy \& Clinical Neurophysiology, 1965 , $19,470-475$.

SUTTON, S., BRAREN, M., ZUBIN, J., \& JOHN, E, R. Evoked-potential correlates of stimulus uncertainty. Science, 1965 , 150, 1187-1188.

SUTTON, S., TEUTING, P., ZUBIN, J., \& JOHN, E. R. Informational delivery and the sensory evoked potential. Science, $1967,155,1436 \cdot 1439$.

\title{
Sequence of shock and nonshock training trials influences the extinction of escape behavior*
}

\author{
JOSEPH J. FRANCHINA \\ Virginia Polytechnic Institute, Blacksburg, Va. 24061
}

Escape behavior was extinguished following training under either $100 \%$ shock or $50 \%$ shock and nonshock trials intermixed in double alternation, single alternation, or random sequences. Resistance to extinction was greater for alternation than for random or $100 \%$ conditions; double alternation yielded reliably greater resistance to extinction than all other conditions.

Following escape training with shock and nonshock trials intermixed, the prediction of extinction performance under nonshock seems relatively straightforward from the discrimination hypothesis viewpoint

\footnotetext{
* These data were collected by Neil $\mathbf{J}$ Hochstadt at DePaul University and were reported, in part, at the Southwestern Psychological Association meeting, New Orleans, April 1968.
}

(e.g., Mowrer \& Jones, 1945). That is, interspersing shock and nonshock training trials should attenuate the discriminability of training from extinction and, thereby, increase resistance to extinction ( $\mathrm{Rn}$ ) relative to training with shock exclusively. The purpose of this experiment was to evaluate whether the presence of nonshock training trials perse facilitates $R n$, or whether the 